\title{
Conexión y valoración internacional del proyecto de Registro de Arquitectura Contemporánea
}

Víctor Pérez Escolano, Dpto. de Historia, Teoría y Composición Arquitectónicas. Universidad de Sevilla

En los años 60 del

\section{s.XX se produce una}

quiebra y rectificación

en los valores

y objetivos del

proyecto

arquitectónico

y urbano
En sentido estricto deberíamos designar como arquitectura contemporánea aquella que se produce en el tiempo presente, el tiempo que vivimos. Pero, ¿quiénes constituiríamos el sujeto de esa temporalidad?, ¿cada uno de nosotros al referirnos a la arquitectura que se produce a lo largo de nuestra existencia?, o, más bien, lo adecuado sería hablar de un sujeto colectivo, por ejemplo el de los seres humanos que habitamos el planeta hoy, y por consiguiente, con experiencias vividas incluso más allá de medio siglo atrás.

El hecho es que se adoptó ese término a mediados del siglo XX para establecer un referente genérico y abierto de lo que estaba siendo la mayor aceleración de transformaciones urbanas habidas hasta la fecha sobre el planeta, en parte debido a los procesos de reconstrucción posbélica y en definitiva por los impulsos de la aceleración económica que iba a presidir, no sin sus crisis, el desarrollo de regiones muy amplias de la geografía mundial, en paralelo a la degradación de otros muchos ámbitos, incluidos los del proceso de descolo- nización y configuración de lo que se vino en llamar tercer mundo.

Ese fue el hecho primordial, que la división del mundo en bloques desde los años cincuenta del siglo XX en el escenario de la guerra fría, y el reconocimiento del tercer mundo o países en vías de desarrollo, tuvieron en el desarrollo territorial y urbano un fuerte parámetro de identificación que en última instancia remitía a un acelerado proceso de destrucción y construcción arquitectónica definitivamente asociado a una idea de innovación, en gran parte derivada de los paradigmas más elementales y operativos de la modernidad, incluyendo importantes alteraciones en los paisajes natural y construido, propiciadas por los instrumentos iniciales de dominación colonial y agravados bajo diversas formas de neocolonialismo.

Por tanto, hablar de arquitectura contemporánea no significaba entonces lo mismo que hoy, cincuenta años después, cuando nuestro tiempo presente ya avanza acelerado dentro 


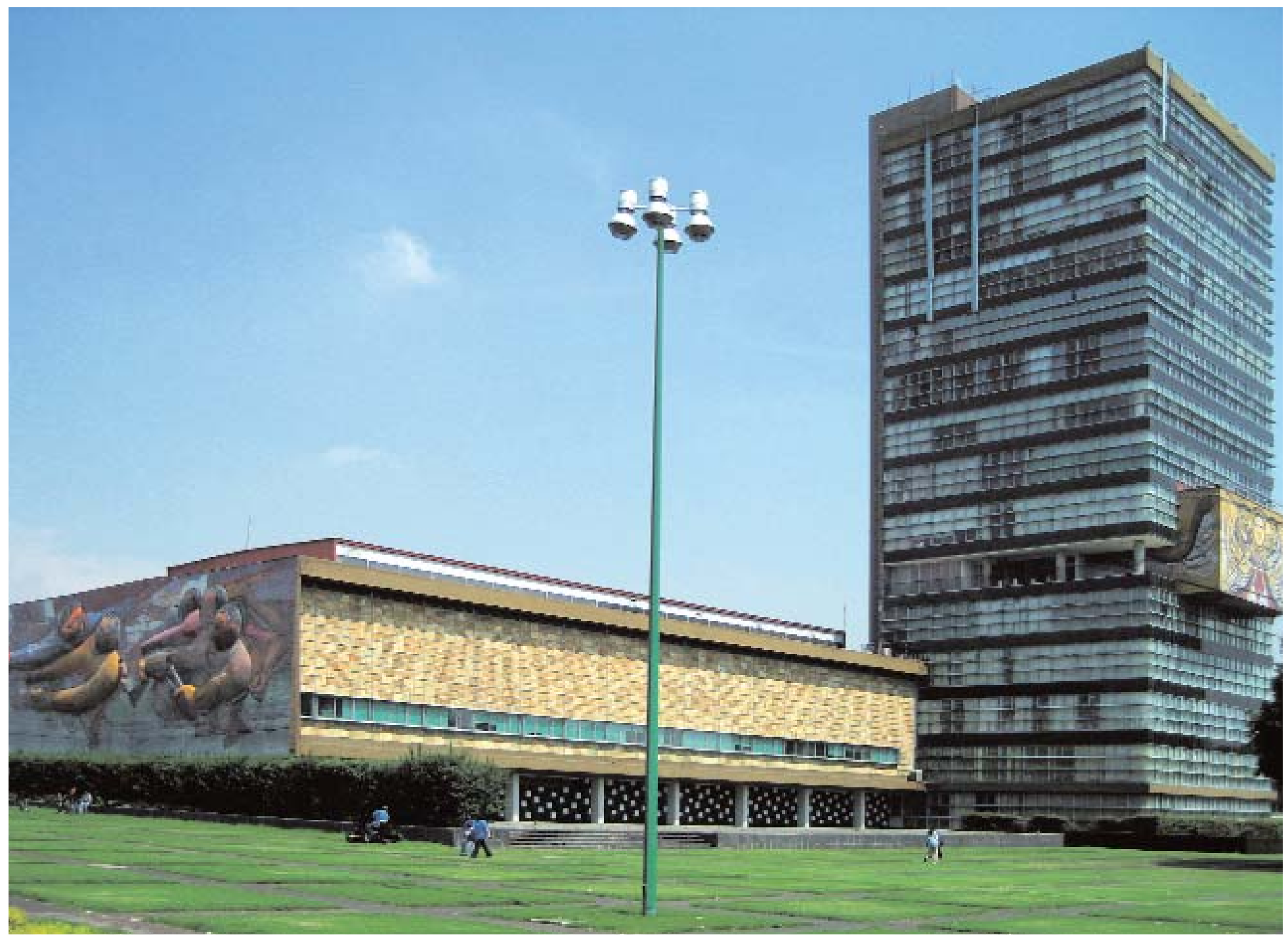




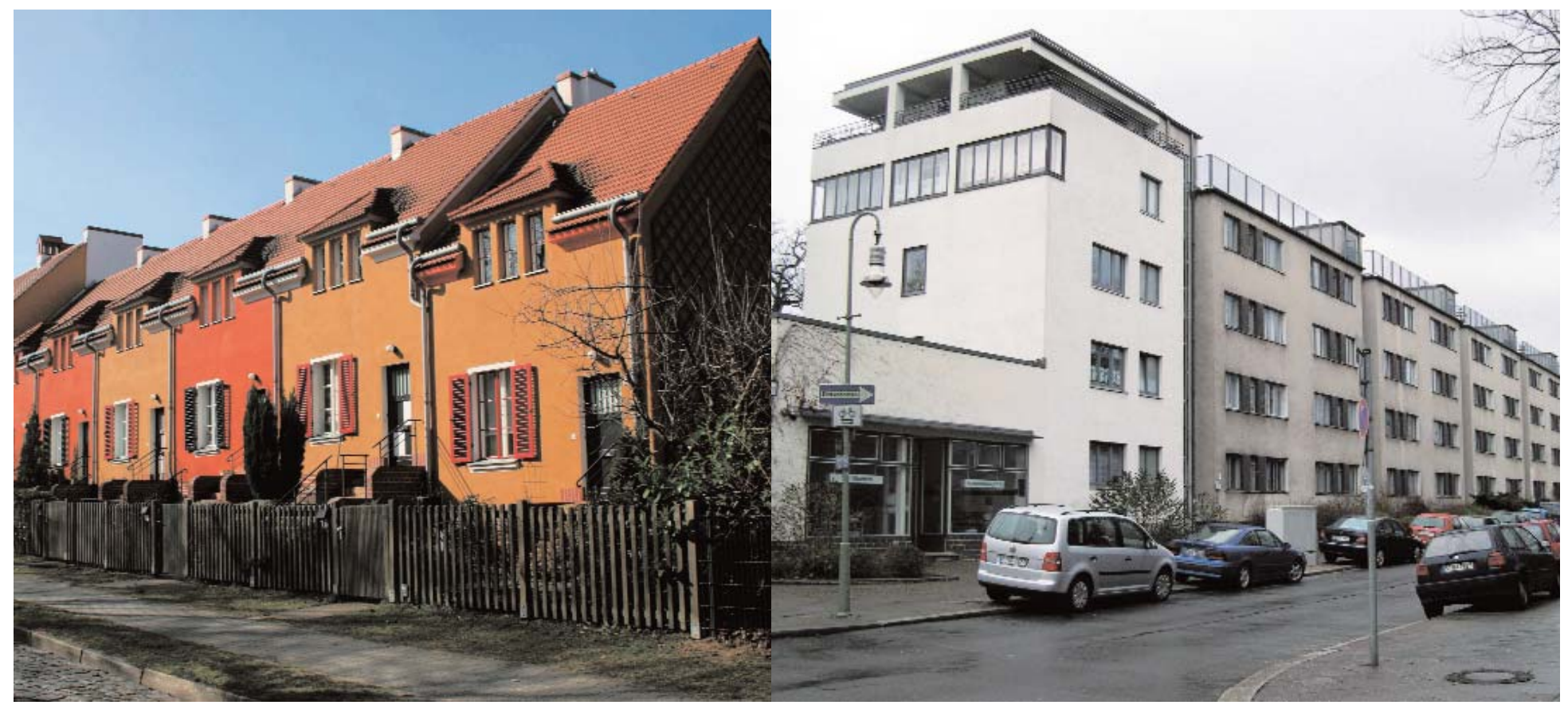

(1) Siedlung Falkenberg (Berlín, Alemania), de Bruno Taut (1913) / MichAEL

(1) Siedlung berlinesa Siemensstadt (1927), proyecto dirigido por Walter Gropius / MicHELE BoccIA

del siglo XXI, y las nuevas variantes de la globalización se expresan arquitectónicamente, especialmente en Asia. ¿Qué ha sucedido en la cultura arquitectónica en las últimas cuatro décadas del XX? En Occidente vivimos una transformación disciplinar de extraordinaria trascendencia que, en lo que aquí nos interesa, podemos reducirlo a dos factores. Primero, la rectificación en los valores y objetivos. Desde los años sesenta, el proyecto arquitectónico y urbano fue girando hacia una estimación inédita de la herencia cultural. Se produjo la superación de la noción de patrimonio reducida a una colección de monumentos excepcionales, sustituida por otra abierta y estructural, en la que el territorio y la ciudad se manifestaban como objeto articulado de estudio, con argumentos morfológicos y tipológicos, incluso en la modesta pero substantiva encarnadura de la vivienda popular y el trazado del espacio público. En definitiva, una ruptura epistemológica que desembocó en la quiebra y diseminación de los atributos patrimoniales, que alcanzaría también la superación de la artificiosidad de los límites temporales del objeto de estudio.
Una universalización multicultural, disciplinar e histórica, bajo la idea unívoca de lo patrimonial que terminaría por ser impulsado por la UNESCO con reflejo en la práctica que traduce de forma concluyente la lista del Patrimonio Mundial desarrollada año a año por el organismo cultural de las Naciones Unidas desde el establecimiento en 1972 de la Convención del Patrimonio Mundial Cultural y Natural, y reflejado en las sucesivas directrices prácticas para su aplicación. Un proceso del que cabe extraer la constatación de la creciente importancia de la arquitectura contemporánea, que hoy refleja contundentemente la expansión temporal y geográfica de la mutación de los principios patrimoniales, dentro del parámetro de singularidad que contempla la lista del Patrimonio Mundial.

En efecto, desde 1984 en que fueron incluidos algunos edificios del arquitecto Antoni Gaudí en Barcelona, hasta las recientes incorporaciones, como las de este año de 2007 del campus universitario de la UNAM en Ciudad de México, algunas siedlungen 


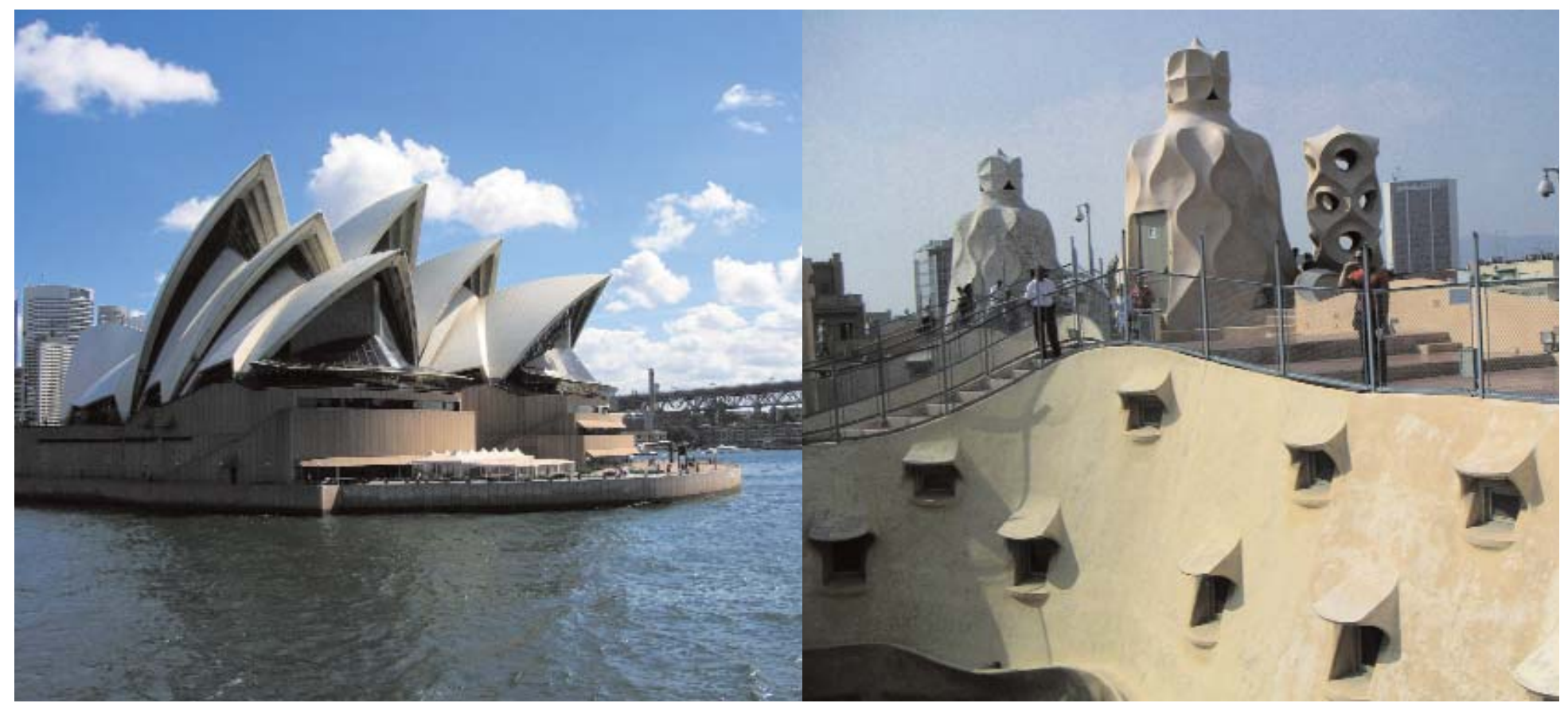

(1) Ópera de Sydney en Australia del arquitecto Jorn Utzon / NICOLE EATON

(1) Casa Milà en Barcelona, obra de Antonio Gaudí / BeAtriz CASTELLANo

berlinesas esencialmente del periodo de entreguerras, o la Ópera de Sydney, se han ido cruzando numerosas fronteras antes consideradas infranqueables. Por ejemplo, el de la antigüedad de las obras, llegándose a producir inclusiones de obras de autores vivos, como es el caso de Jorn Utzon, autor de la última referida, o de Oscar Niemeyer, arquitecto de los principales edificios de Brasilia, integrada en 1987 en la lista del Patrimonio Mundial.

Un escenario del patrimonio de nuestro tiempo que la UNESCO reúne en lista particular relativa a los siglos XIX y XX, de manera que viene a coincidir con la Edad Contemporánea, entendida como convención para recoger lo acontecido desde la transformación generada por el pensamiento ilustrado con los consiguientes cambios políticos, sociales, económicos y culturales, que tanta influencia tuvieron en la arquitectura como soporte y expresión de los nuevos escenarios de la vida humana desde la Revolución Francesa. Aunque la UNESCO denomine a esa sección modern heritage properties (bienes patrimoniales modernos), habiendo también desagregado la de los industrial heritage properties (bienes patrimoniales industriales), en sus anexos de documentos específicamente dedicados a la materia como el número 5 de los "World Heritage Papers" dedicado a la Identification and Documentation of Modern Heritage (2003).

Cabría entender que ambas entradas, y sus denominaciones, están vinculadas a las conexiones específicas que a través de ICOMOS, como consultor genérico, se establecieron en su día con el Docomomo International y el TICCIH, y que siendo decisivas para el proceso en desarrollo, conservan sus concretos vínculos relativos a la arquitectura del movimiento moderno y al patrimonio industrial respectivamente. Comprendiendo los beneficios particulares que esas organizaciones han impulsado, somos partidarios de que una reflexión integral, como la que nos ocupa en este proyecto, se haya decantado por la denominación de Registro Andaluz de Arquitectura Contemporánea, y se haya aplicado a todo el siglo XX, sin limitar sus orientaciones formales, tipológicas, de localización o envergadura, incluyendo los ámbitos abiertos, integrando el patrimonio industrial y el del movimiento moderno con cualesquiera otras obras cuya selección únicamente se establezca bajo un principio de calidad en los valores susceptibles de ser evaluados tanto local como transversalmente, en el conjunto de Andalucía y hacia la puesta en valor del paisaje cultural arquitectónico contemporáneo, su difusión y protección conforme a los instrumentos más idóneos establecidos en la nueva Ley del Patrimonio Histórico Andaluz.

La convergencia que ofrece nuestro trabajo con el Inventario de la Arquitectura del siglo XX en España (liderado por el Docomomo Ibérico e integrado en un proyecto europeo SUDOE) quisiera contribuir a estimular la dimensión de la protección patrimonial en el ámbito competencial de las distintas Comunidades Autónomas del Estado y a favorecer el necesario papel de coordinación, soporte y reflexión que debe corresponder al Ministerio de Cultura. 